\title{
Cultural evolutionary psychology is still evolutionary psychology
}

\author{
Marco Fenici ${ }^{1}$ and Duilio Garofoli ${ }^{2}$ \\ ${ }^{1}$ Department of Philosophy, Faculty of Humanities and Letters, Bilkent University, 06800, Bilkent, Ankara, \\ Turkey \\ Email: marco.fenici@bilkent.edu.tr \\ URL: https://www.researchgate.net/profile/Marco Fenici
}
${ }^{2}$ Research Center "The Role of Culture in Early Expansions of Humans" of the Heidelberg Academy of Sciences and Humanities, Eberhard Karls Universität Tübingen, Rümelinstr. 23, 72070 Tübingen, Germany
Email: duilio.garofoli@uni-tuebingen.de
URL: http://www.roceeh.net/network/graduate-network/alumni/duilio-garofoli/

In compliance with specifications of the Italian Ministry of Education, Universities and Research, we clarify that Marco Fenici has written the first four and the last paragraph, and that Duilio Garofoli has written the remaining five.

\begin{abstract}
The Cognitive Gadgets Theory (CGT) proposes to reform evolutionary psychology by replacing the standard nativist and internalist approach to modularity with a cultural constructivist one. However, the resulting "cultural evolutionary psychology" still maintains some controversial aspects of the original NeoDarwinian paradigm. These assumptions are unnecessary to the CGT and can be eliminated without significant conceptual loss.
\end{abstract}

Heyes' (2018) cognitive gadgets theory (henceforth CGT) constitutes a significant advancement over the standard neo-Darwinian account in evolutionary psychology. According to the latter, the mind is a collection of innately specified domain-specific units, which operate through inner representations and algorithms, and are shaped by natural selection because of their causal contribution in adapting the organism to critical issues in the environment (e.g., Barkow et al. 1992; Buss 2012; Cosmides and Tooby 2013). Culture in turn is the physical derivative of such modules, and stands as instrumental to the solution of these adaptive problems. The CGT argues that the standard view "does not line up with the evidence from cognitive science" (p. 15). In contrast, it aims to replace the standard view with a "cultural evolutionary psychology," according to which cultural practices create cognitive functions by building upon internal and biologically selected domaingeneral mechanisms. The CGT thus conceives the mind not as a collection of cognitive modules but rather of culturally constructed "cognitive gadgets."

Although we praise the constructivist lean assumed by the author, we intend to argue that the CGT does not completely free itself from a variety of problematic neo-Darwinian assumptions. Despite the fact that many accounts in social anthropology (Ingold 2007), cognitive archaeology (Knappett 2005; Malafouris 2013; Iliopoulos and Garofoli 2016), postphenomenology (Ihde 1990, Veerbek 2005; Ihde and Malafouris 2018), and enactive cognition (Hutto 2008; Hutto and Myin 2013; Fenici and Garofoli 2017) have extensively opposed these assumptions over time, the author has not considered such criticisms in the current formulation of the CGT. Within this comment, we intend to bring to the fore and suggest possible solutions 
to these critical issues that also affect the CGT. In particular, we will discuss and criticize its assumptions concerning (i) the computational and semantic-information theory of mind and culture, (ii) the adaptionist view in cognitive evolution, (iii) the completeness of cognitive functions as units of selection, and (iv) the fixed link between brain regions and cognitive functions.

To start, the CGT shares with the standard Neo-Darwinian view a computational and representational conception of mind and culture. Indeed, like modules, domain-general systems remain in any case representational components of a computational architecture. Their content is determined by teleosemantics (pp. 27-30; see Millikan 2004), and natural selection alters their representational capacities by acting on the minimal constituents of their physical vehicles, i.e., their genetic bases. At the same time, although the author states that "a cognitive mechanism certainly is not a pellet of information that can be copied inside your head, sent through the air, and planted wholesale in my head" (p. 44), she keeps adopting a model typical of cultural evolution theory, according to which culture is semantic information, traveling across human minds through social learning (e.g., Richerson and Boyd 2008; Mesoudi 2011). The novelty of the current model thus stands in the idea that different codes inhabiting respectively the biological and the cultural channel are now integrated, thereby generating the cognitive gadgets through "wide computations" (cf. Wilson 1994). However, these representational and computational foundations remain highly controversial at present. Representationalism has indeed been considered metaphysically inconceivable (Hutto \& Myin 2013, 2017), the information-semantic view of culture utterly disembodied (Malafouris 2016; Walls in press), and the great success of these views primarily associated to biases in computer-based societies rather than empirical validation (Penny 2017).

The CGT exploits these conceptual bases also to maintain a hard adaptationist stance in cognitive evolutionalthough modified in order to accommodate its constructivist amendments-, according to which "cultural evolution has the potential to explain the adaptedness of distinctively human cognitive mechanisms" (p. 37). The core point is that "genetic and cultural evolution are based on the same, fundamental heuristicvariation-and-selective-retention" (p. 36). Thus, wide computations appear as elements of a broader code that are generated, modified, replicated, and transmitted downstream along the dual-inheritance system just described. This implies that we can analyze cognitive gadgets with the tools of the neo-Darwinian theory-although presented in the form a "Campbellian' selectionist approach" (p. 36). The "modern human mind", allegedly shared by all human populations, therefore appears as a collection of adaptive gadgets that survived selection, in line with the idea that evolutionary principles ultimately justify why the mind has the shape we observe in the present.

In response to such a Neo-Darwinian take on cognition and culture, we note that over time many critics from different domains have repeatedly challenged these assumptions. During the ' $80 \mathrm{~s}$ in archaeological theory, the post-processual movement strongly reacted to the idea from the New Archaeology and its heirs that human behavior and cognition are determined by adaptive laws, which could be assembled in the present through ethnographic studies and deductively applied to the study of the past (Shanks and Tilley 1987; Trigger 1998; Hodder and Hutson 2003, chapter 2; Bednarik 2013, p. 21). Post-processual critics argued that human culture is created and maintained within a psychological and ideological dimension, which can overcome strict adaptive reasons. Similarly, critics in social anthropology have contended that human life is a shared narration and an embodied way of being in the world. Thus, they have rejected metaphors depicting humans as computational machines, and culture as the outcome of transmission and selection processes (Ingold 2004, 2007; Tallis 2011; Ingold and Palsson 2013). If these criticisms are correct, the human mind cannot be reduced to the evolutionary selection of wide computations acting on the cognitive level, as the author suggests, but rather cognitive gadgets are likewise embedded within a social narration. Thus, they can actively be formed and maintained because of what humans believe, think, desire, and emotionally experience independently from supposed adaptive reasons. 
The previous discussion hints against a third important neo-Darwinian aspect of the CGT, namely, the idea that gadgets are distinct units of selection provided with specific adaptive values. Following the principles of material engagement theory (Renfrew 2004; Malafouris 2013; Iliopoulos and Garofoli 2016), we argue that gadgets are not only integrated with a broad gamut of conceptual and affective states but are also materially extended through their hybridization with artifacts and features of the external world. Furthermore, they are constitutively related to one another, and the boundaries between them are hard to identify. For instance, similarly to the author, Everett (2012) has proposed that language is a cultural construct that capitalizes on domain-general systems capturing perceptual regularities, thereby appearing as a cognitive gadget. However, language is not an isolated cognitive function, because it is constitutive of and simultaneously constituted by other cognitive gadgets. To mention one, many scholars defending a constructivist perspective believe that meta-representational mindreading is realized through linguistic practices (Fenici 2017; Fenici and Garofoli 2017; Gallagher and Hutto 2008; Hutto 2008). Mindreading in turn allows language to bend on itself, and bootstrap meta-linguistic awareness, namely, the ability to understand the abstract regularities behind the organization of language (Taylor 2012). Thus, language and mindreading coexist into one another.

The difficulties in isolating units of selection also speaks against the possibility of ascribing decontextualized adaptive values to gadgets, which could be modified and enhanced independently from the rest of the mind/world complex. In contrast, any variation within a gadget can cause cascade effects in a series of intermeshed and materially extended cognitive functions so that the adaptive value of a gadget is given from how it alters the whole cognitive world it lies within. Overall, the massive interconnection and coexistence of factors suggests that selection-based approaches cannot be applied to gadgets in a reductionist fashion and raises the possibility that Neo-Darwinian methods are incommensurable with the domain of cognition and culture.

Finally, we argue that the CGT maintains a conservative idea of the relation between brain regions and functions-though milder than the standard evolutionary psychology account-because it contends that brain regions are selected by culture for mediating particular cognitive functions. However, following the theory of neural reuse (Anderson 2014; Raja 2017), brain regions are deployed and redeployed in multiple cognitive tasks, depending on their internal constraints and relations to bodily and material structures. By acting on such physical constraints, natural selection makes some neural networks more or less suitable to hosting particular functions but these networks have no original functional exclusivity of any sort. Thus, brain regions are evolved by culture without being for anything in particular, including domain-general processes.

The criticisms to the Neo-Darwinian view that we expressed shape a radically different conception of the mind in relation to the brain, the body, and culture. Rather than a computational device constructed through cultural selection, this view depicts the human mind through the metaphor of a "brainwave" that invades reality and resonates with external structures (Gibson 1966, p. 5; Robbins 2006; Raja 2017 and references therein). Cognition in this sense stands as a dynamic system incurring between particular structural patterns in the world and neural territories showing appropriate conditions for resonance but does not involve a brainbound computational architecture. Furthermore, material structures are non-neutral, because they incite the mind, foster the creation of new patterns of resonance, and therefore continuously reshape cognition (Ihde 1990, 2009; Knappett 2005; Veerbek 2005; Ihde and Malafouris 2018). Consequently, culture cannot be conceived as a disembodied code of operations and algorithms but implies the socially negotiated alteration of such structures, and the creation of new affordances for cognitive transformation that are inherited by the new generations (see the concept of a "landscape of affordances "in Rietveld and Kuverstein 2014, and Rietveld et al. 2018). Within this view, cognitive evolution is intended as a metaplastic trajectory, where the mind emerges only at the nexus of neural and cultural plasticity, and does not identify an 
autonomous level for natural selection (Malafouris 2010; Roberts 2016; lliopoulos and Garofoli 2016; Woodward in press; Aston in press).

This conception remains friendly with the constructivist inclination of the CGT, and yet renounces the idea that some cognitive constructs (i.e., the gadgets) are fixed units of adaption and selection, and with this avoids the serious reductionist pitfalls of the Neo-Darwinian theory. In contrast, cognitive functions are one and many, intermingled with motivational and emotional aspects, and deeply embedded within materiality (cf. Spivey 2007). They are prone to developmental change and inherently incomplete (Malafouris 2016), so that any transformation in one of them potentially affects the whole structure of the mind as well as the relational entanglement of agents and the world (Garofoli in press). Such resulting conception predicating the coalescence of cognitive properties, the radical interconnection of beings, and the fluid transformation and "rebirth" of the mind and the world, seems closer to a form of naturalized Buddhism rather than a neoDarwinian theory of cognitive evolution (Varela et al. 2017 [1991]; Vogd 2013). We hope to have convincingly shown that it allows the CGT to maintain its constructivist foundations while renouncing unnecessary and controversial assumptions.

\section{Acknowledgments}

Duilio Garofoli is funded by the Gerda Henkel Foundation.

\section{References}

Anderson, M. L. (2014). After phrenology: Neural reuse and the interactive brain. Cambridge, Massachusetts: MIT Press.

Aston, A. (in press). Metaplasticity and the boundaries of social cognition: exploring scalar transformations in social interaction and intersubjectivity. Phenomenology and the Cognitive Sciences.

Barkow, J. H., Cosmides, L., \& Tooby, J. (1992). The adapted mind: Evolutionary psychology and the generation of culture. New York: Oxford University Press.

Bednarik, R. G. (2013). Creating the human past: an epistemology of Pleistocene archaeology. Oxford: Archaeopress.

Buss, D. (2012). Evolutionary psychology: the new science of the mind. London: Allyn \& Bacon.

Cosmides, L., \& Tooby, J. (2013). Evolutionary psychology: New perspectives on cognition and motivation. Annual Review of Psychology, 64, 201-229.

Everett, D. L. (2012). Language: The cultural tool. New York: Pantheon Books.

Fenici, M. (2017). What is the Role of Experience in Children's Success in the False Belief Test: Maturation, Facilitation, Attunement or Induction? Mind \& Language, 32(3), 308-337.

Fenici, M., \& Garofoli, D. (2017). The biocultural emergence of mindreading: integrating cognitive archaeology and human development. Journal of Cultural Cognitive Science, 1(2), 89-117.

Gallagher, S., \& Hutto, D. (2008). Understanding others through primary interaction and narrative practice. In J. Zlatev, T. P. Racine, C. Sinha, \& E. Itkonen (Eds.), The shared mind: Perspectives on intersubjectivity (pp. 17-38). Amsterdam: John Benjamins.

Garofoli, D. (in press). Embodied cognition and the archaeology of mind: a radical reassessment. In A. Prentiss (Ed.), Handbook of evolutionary research in archaeology. Springer.

Gibson, J. J. (1966). The senses considered as perceptual systems. Boston: Houghton Mifflin.

Hodder, I., \& Hutson, S. (2003). Reading the past: current approaches to interpretation in archaeology. Cambridge: Cambridge University Press.

Hutto, D. D. (2008). Folk psychological narratives: The Sociocultural basis of understanding reasons. Cambridge, Massachusetts: MIT press. 
Hutto, D. D., \& Myin, E. (2013). Radicalizing enactivism: Basic minds without content. Cambridge, Massachusetts: MIT Press.

Hutto, D. D., \& Myin, E. (2017). Evolving enactivism: Basic minds meet content. Cambridge, Massachusetts: MIT Press.

Ihde, D. (1990). Technology and the lifeworld: From garden to earth. Bloomington \& Indianapolis: Indiana University Press.

Ihde, D. (2009). Postphenomenology and technoscience. The Peking University lectures. Albany, New York: SUNY Press.

Ihde, D., \& Malafouris, L. (2018). Homo faber Revisited: Postphenomenology and Material Engagement Theory. Philosophy \& Technology, 1-20.

Iliopoulos, A., \& Garofoli, D. (2016). The material dimensions of cognition: reexamining the nature and emergence of the human mind. Quaternary International, 405, Part A (The material dimensions of cognition), 1-7.

Ingold, T. (2004). Beyond biology and culture. The meaning of evolution in a relational world. Social anthropology, 12(2), 209-221.

Ingold, T. (2007). The trouble with 'evolutionary biology'. Anthropology Today, 23(2), 13-17.

Ingold, T., \& Palsson, G. (Eds.). (2013). Biosocial becomings: integrating social and biological anthropology. Cambridge: Cambridge University Press.

Knappett, C. (2005). Thinking Through Material Culture. Philadelphia: University of Pennsylvania Press.

Malafouris, L. (2010). Metaplasticity and the human becoming: principles of neuroarchaeology. Journal of anthropological sciences, 88(4).

Malafouris, L. (2013). How things shape the mind: A theory of material engagement. Cambridge, Massachusetts: MIT Press.

Malafouris, L. (2016). On human becoming and incompleteness: A material engagement approach to the study of embodiment in evolution and culture. In G. Etzelmüller \& C. Tewes (Eds.), Embodiment in evolution and culture (pp. 289-305). Tübingen: Mohr Siebeck.

Mesoudi, A. (2011). Cultural evolution: How Darwinian theory can explain human culture and synthesize the social sciences. Chicago and London: University of Chicago Press.

Millikan, R. G. (2004). Varieties of meaning. Cambridge, MA: The MIT Press.

Penny, S. (2017). Making Sense: Cognition, Computing, Art, and Embodiment. Cambridge, Massachusetts: MIT Press.

Raja, V. (2017). A Theory of Resonance: Towards an Ecological Cognitive Architecture. Minds and Machines, 28(1), 29-51.

Renfrew, C. (2004). Towards a theory of material engagement. In E. DeMarrais, C. Gosden, \& A. C. Renfrew (Eds.), Rethinking materiality: the engagement of mind with the material world (pp. 23-31). Cambridge: McDonald Institute for Archaeological Research.

Richerson, P. J., \& Boyd, R. (2008). Not by genes alone: How culture transformed human evolution. Chicago: University of Chicago Press.

Rietveld, E., Denys, D., \& Van Westen, M. (2018). Ecological-enactive cognition as engaging with a field of relevant affordances: The skilled intentionality framework (SIF). In A. Newen, L. De Bruin, \& S. Gallagher (Eds.), Oxford handbook of 4E cognition (pp. 41-70). Oxford: Oxford University Press.

Rietveld, E., \& Kiverstein, J. (2014). A rich landscape of affordances. Ecological Psychology, 26(4), 325-352.

Robbins, S. E. (2006). Bergson and the holographic theory of mind. Phenomenology and the Cognitive Sciences, 5(3-4), 365-394.

Roberts, P. (2016). 'We have never been behaviourally modern': The implications of Material Engagement Theory and Metaplasticity for understanding the Late Pleistocene record of human behaviour. Quaternary International, 405, Part A (The material dimensions of cognition), 8-20.

Shanks, M., \& Tilley, C. Y. (1987). Social theory and archaeology. Cambridge: Polity Press

Spivey, M. (2007). The continuity of mind. New York: Oxford University Press. 
Tallis, R. (2011). Aping mankind: Neuromania, Darwinitis and the misrepresentation of humanity. Durham: Acumen.

Taylor, T. J. (2012). Understanding others and understanding language: how do children do it? Language Sciences, 34(1), 1-12.

Trigger, B. G. (1998). Archaeology and epistemology: dialoguing across the Darwinian chasm. American Journal of Archaeology, 102(1), 1-34.

Varela, F. J., Thompson, E., \& Rosch, E. (2017). The Embodied Mind: Cognitive Science and Human Experience. Cambridge, Massachusetts: MIT Press.

Verbeek, P.-P. (2005). What things do: Philosophical reflections on technology, agency, and design. University Park: Penn State Press.

Vogd, W. (2013). Constructivism in Buddhism. In A. L. C. Runehov \& L. Oviedo (Eds.), Encyclopedia of Sciences and Religions (pp. 489-495). Dordrecht: Springer.

Walls, M. (in press). The bow and arrow and early human sociality: an enactive perspective on communities and technical practice in the Middle Stone Age. Philosophy and Technology.

Wilson, R. A. (1994). Wide computationalism. Mind, 103(411), 351-372.

Woodward, M. (in press). Metaplasticity rendered visible in paint: How matter 'matters' in the lifeworld of human action. Phenomenology and the Cognitive Sciences. 